\title{
As relações de gênero na Fundação Municipal de Esporte de Florianópolis: políticas genéricas, atendimento generificado.
}

\author{
Verônica Werle* \\ Maria do Carmo Oliveira Saraiva ${ }^{* *}$
}

\begin{abstract}
Resumo: A presente pesquisa realizou-se na Fundação Municipal de Esportes de Florianópolis, SC (Brasil) objetivando compreender como as questões de gênero estão incorporadas (ou não) nas políticas públicas de esporte e lazer desta instituição. As entrevistas com dirigentes e técnicos da Fundação e as análises de relatórios de atividades permitiram apontar que há um maior atendimento aos homens em relação às mulheres, o que se dá pela valorização diferenciada das modalidades e dimensões esportivas; para os entrevistados há igualdade nas políticas, sendo que a maior participação masculina é atribuída a aspectos culturais, que são naturalizados por eles.
\end{abstract}

Palavras-chave: Gênero. Políticas públicas. Esportes. Lazer.

\section{INTRODUÇÃo}

O presente trabalho é resultado de uma pesquisa que teve o objetivo de analisar como as relações de gênero estão incorporadas (ou não) aos discursos, orientações e direcionamentos da Fundação Municipal de Esportes de Florianópolis, órgão público responsável pelo esporte e lazer naquela cidade.

\footnotetext{
"Universidade Federal de Santa Catarina. Florianópolis,SC, Brasil. E-mail:vewerle@yahoo.com.br "Curso de Educação Física da Universidade Federal de Santa Catarina. Florianópolis, SC, Brasil.E-mail:marcarmo1952@gmail.com
} 
A inclusão da problemática da desigualdade de gênero nas agendas políticas iniciou-se na década de 1980, como parte do processo de redemocratização do país, mas apesar de ainda ser um processo em construção (FARAH, 2003), já é possível observar importantes movimentos, tanto na produção científica como em ações concretas. Na área da segurança tem-se o exemplo da criação de programas que atendem mulheres vítimas de violência, incluindo as Delegacias Especializadas de Atendimento a Mulher e a Lei Maria da Penha (FARAH, 2003). Na educação houve a reformulação de livros didáticos objetivando eliminar referências discriminatórias e também a inclusão da sexualidade como tema transversal nos Parâmetros Curriculares Nacionais (VIANNA; UNBEHAUM, 2004). Já na área da saúde, os avanços se encontram nas discussões sobre os direitos reprodutivos dos homens e a ampliação do tempo de licença paternidade (LYRA-DA-FONSECA, 2008).

Muito tem contribuído para o desenvolvimento destas reflexões e ações a criação da Secretaria Especial de Política para as Mulheres em 2003, órgão federal que se dedica a disseminar e propor ações de igualdade de gênero de modo transversalizado com os setores governamentais. Entre as principais áreas temáticas trabalhadas pela Secretaria Especial estão a violência, o trabalho, a educação, o poder e decisão e a saúde, de forma que as questões relacionadas às práticas corporais e ao movimento humano ainda não tem sido foco. Da mesma forma podemos dizer que a área da Educação Física - Ciência do Esporte ainda não tem analisado efetivamente as temáticas de gênero e de políticas públicas de forma transversalizada.

Sendo assim e levando em consideração os avanços concretos quanto aos aspectos de gênero das políticas públicas de outras áreas, decidiu-se lançar um novo olhar sobre a situação das políticas esportivas e de lazer de maneira a tentar perceber como os aspectos de gênero se manifestam, influenciam e são incorporados, ou não às práticas governamentais. Como bem explica Farah (2003, p.2) não 
estamos habituados a olhar as ações governamentais e não governamentais a partir da perspectiva do gênero, e este "novo olhar" é preciso "[...] para se poder perceber se os diferentes - homens e mulheres - estão sendo 'atendidos', se estão tendo oportunidades e espaços iguais, inclusive para se manifestar" .

Apesar de uma abordagem teórica aprofundada não caber nos limites deste texto, cabe destacar que a problemática do gênero foi abordada a partir das contribuições de Louro (1997) e Goellner (2007; 2005), cujas perspectivas encaminham para o entendimento de que a desigualdade de gênero é de ordem histórica e social, e estrutura outras desigualdades, construindo e diferenciando corpos e práticas femininas e masculinas. Também partimos do entendimento de que o gênero é constituído por discursos e práticas, cujos efeitos são identidades em constante construção, ao contrário de masculinidades e feminilidades estabelecidas e uniformes (BUTLER, 2003). Para instrumentalizar nosso entendimento de política pública de esporte e lazer utilizamos as contribuições de Menicucci (2006) e Linhales (1996) e sobre políticas públicas com enfoque nas relações de gênero buscamos nos fundamentar em Farah (2003; 2004). Por políticas públicas entendemos o conjunto de práticas de governo, estratégias e intervenções do Estado com e para a população, cuja finalidade é alcançar determinados resultados que deveriam abarcar a afirmação da cidadania ${ }^{1}$ de todos e todas, permitindo a igualdade de gênero. Todavia, concordamos com Menicucci (2006) quando aponta que as políticas públicas não se caracterizam apenas pelos atos de uma autoridade pública, mas também pelos seus "não atos" e, entendendo que "[...] o fato de que algumas questões (e não outras) passem a ser objeto de decisões e ações públicas é algo que precisa ser explicado em cada situação específica e está relacionado à construção social de propostas no âmbito societário e ou governamental" (MENICUCCI, 2006, p.143-144).

\footnotetext{
${ }^{1} A$ noção de cidadania é explicada por Menicucci (2006) apoiada no trabalho de Marshall, como o conjunto dos direitos civis, políticos e sociais, sendo que este último, no qual se insere o esporte e o lazer, "permitem reduzir os excessos de desigualdades geradas pela sociedade de mercado e garantir um mínimo de bem estar para todos" (p. 138).
} 


\section{ESTADO COMO INSTITUIÇÃO CONSTTUUINTE E CONSTITUÍDA POR RELAÇÕES DE GÊNERO.}

A importância que as práticas corporais assumem na construção da ordem de gênero, ou melhor, nas identidades de gênero é evidente, não apenas por refletir as diferenciações da sociedade, mas também por determinar relações hierárquicas entre homens e mulheres. Como bem explica Goellner (2007), estas construções que se acomodam nos corpos e que nos constituem como femininos e masculinos são calcadas no conjunto de discursos e práticas sociais atreladas a redes de poder que determinam, inclusive, o modo de cada sexo viver e experimentar as práticas corporais.

A partir do momento em que se entende que somos constituídos pelo gênero, é preciso considerar que as instituições também o são, pois estas representam as (não) escolhas, as (não) decisões dos sujeitos que a formam. Sendo assim, o Estado, por diferentes meios, inclusive pelas práticas corporais, também produziu desigualdades de gênero ao manter por muito tempo, se não até hoje, valores e práticas fundadas na ideologia patriarcal ${ }^{2}$. Esta noção da generificação das instituições é sustentada por Guacira Louro (1997, p. 25), quando explica:

Busca-se compreender que a justiça, a igreja, as práticas educativas ou de governo, a política, etc. são atravessadas pelo gênero: essas instâncias, práticas ou espaços sociais são generificados produzem-se, ou engendram-se, a partir das relações de gênero (mas não apenas a partir dessas relações e sim, também, das relações de classe, étnicas, etc.).

As diferenças corporais, que geraram as diferenciações entre homens e mulheres e justificaram as desigualdades entre ambos em muitas instâncias sociais, foram, em muitas situações, orientadas por e orientadoras dos setores públicos vinculados ao esporte e à educação física ao longo da história do Brasil.

\footnotetext{
${ }^{2}$ Por Ideologia Patriarcal entendemos o conjunto de normas impostas como verdades e que representa a supremacia dos homens, brancos e heterossexuais e, portanto, a inferioridade dos grupos sociais que não fazem parte daquele; a partir desta lógica foram estabelecidas as distinções sexuais e sociais nos quais o masculino tem vantagens (Scott, 1990).
} 
As desigualdades ficam bastante claras pelo enfoque funcionalista e utilitário conferido ao esporte e ao lazer pelo Estado, o que corroborou para uma educação física diferenciada para cada sexo no início do século XX, que serviria para moralizar o corpo masculino e prepará-lo para o trabalho, enquanto que, no caso das mulheres, deveria garantir as exigências físicas para a futura maternidade (GOELLNER, 2005b). Ao incorporar tais concepções e implantá-las na escola, o Estado torna-se corroborador de uma educação diferenciada para homens e mulheres, no entanto, suas ações não se reservam ao ambiente educacional.

Quanto à regulamentação esportiva, a primeira legislação referente ao setor no país, já deixava bem clara a visão estatal sobre a participação das mulheres, proibindo-as de práticas "[...] incompatíveis com as condições de sua natureza..." (BRASIL, 1941), o que foi reafirmado em 1965 com a proibição de modalidade como lutas, saltos e futebol para as mulheres (GOELLNER, 2005b), e que foi revogada somente em 1979.

A ampliação da inserção e ascensão de mulheres na esfera pública, incluindo-se o esporte, deu-se a partir de mudanças de concepções em relação às construções sociais sobre os sexos provocadas por movimentos feministas e discussões sociais e acadêmicas. Mas como já foi dito, foi somente no conhecido processo de redemocratização que a inclusão da problemática de gênero passou a ser vista como uma das desigualdades a serem superadas pelas políticas públicas governamentais no Brasil (FARAH, 2003).

Esta problematização do tema por alguns segmentos, não significou, no entanto, a sua incorporação em todos os campos políticos. O fato de o esporte e o lazer, por exemplo, ainda não terem sido temas das políticas públicas que buscam a igualdade de gênero tem a ver com o caráter recente do seu reconhecimento como direito social, bem como às reivindicações femininas manterem, apesar dos avanços em outras áreas, o foco em questões ligadas a própria condição de mulher, como a saúde e a educação. Isto não significa que não seja urgente uma analise que transversalize as políticas públicas de esporte e lazer com a perspectiva de gênero, visto que a 
quantidade, a qualidade e os sentidos que as práticas corporais representam para cada um estão ligadas a diferenças de acesso, de oportunidades, de espaços e materiais.

\section{Procedimentos investigatórios na Fundação Municipal de FLORIANÓPOLIS (FME).}

O contexto desta investigação foi do a Fundação Municipal de Esportes de Florianópolis (FME), instituída desde 1987 com o objetivo de executar a política de esportes do Município de Florianópolis, formulada pela Secretaria Municipal de Turismo, Cultura e Esportes. Atualmente seu quadro de recursos humanos é composto por 38 funcionários/as e estagiários/as divididos/as entre a superintendência, área técnica, administrativa e de serviços gerais. Tendo como base o ano de 2009, também é interessante apresentar como se distribuem os recursos financeiros da Fundação, sendo que 52,18\% são destinados para o Desporto de Rendimento/representação, 42,76\% para Administração Geral, 2,99\% para o Desporto Comunitário e $0,28 \%$ para o Lazer $^{3}$.

O desporto de rendimento e de representação refere-se, na grande maioria dos casos, a ações promovidas especialmente pela Fundação Catarinense de Esporte (FESPORTE), responsável pelas manifestações esportivas no estado de Santa Catarina e cujo sistema esportivo amador encontra-se bem consolidado no estado e articulado com os municípios através das Fundações.

Procurando responder as indagações sobre a incorporação da perspectiva de gênero nas políticas públicas de esporte e lazer da FME, a busca das informações deu-se de forma empírica, por meio da análise de fontes escritas: os relatórios de atividades; e também de entrevistas, sempre adotando os procedimentos éticos solicitados

\footnotetext{
${ }^{3}$ Informações obtidas por meio da Secretaria Municipal de Finanças e Planejamento de Florianópolis, que permitiu o acesso aos Comparativos de Despesa Autorizada com a Empenhada - Anexo TC 08. As porcentagens descritas referem-se ao total de recursos da FME até dezembro de 2009, que somavam $R \$ 5.036 .247,52$.
} 
pelo Comitê de Ética e Pesquisa com Seres Humanos da Universidade Federal de Santa Catarina, no qual a pesquisa foi aprovada.

Os relatórios de atividade foram disponibilizados pelos funcionários da Fundação e perfazem um total de 8 documentos que se referem aos balanços anuais das atividades da Fundação, aos relatórios de participação das equipes representativas do município em campeonatos e aos projetos ${ }^{4}$. Optou-se por analisar os relatórios das atividades correspondentes ao ano de 2009, sendo que esta delimitação temporal permitiu a analise um ciclo de trabalho da Fundação que se completa no período de um ano. A utilização dos documentos se justifica pela sua importância como instrumento de análise, já que permite o acesso à perspectiva oficial da instituição, bem como a maneira como são comunicadas estas perspectivas (BOGDAN; BIKLEN, 2003).

Para compreender a perspectiva daqueles que elaboram as políticas públicas foram realizadas entrevistas semi estruturadas com 8 sujeitos pertencentes às áreas técnicas e da superintendência da FME. Os sujeitos selecionados foram todos homens, já que não havia nenhum cargo diretivo ocupado por mulheres. Seguindo as recomendações de Minayo (2006) foi elaborado um roteiro de entrevista, de forma a ser um guia que contribui para aprofundar e ampliar o conteúdo investigado, fazendo emergir os pontos de vista e as percepções dos sujeitos. O registro das entrevistas foi feito pessoalmente, com agendamento prévio e por gravação eletrônica consentida pelos entrevistados. Foi realizada uma entrevista com cada sujeito selecionado, com duração variando entre 30 minutos a 1 hora e 10 minutos.

A fim de alcançar as idéias essenciais e os sentidos das informações coletadas, utilizamos a análise de conteúdo como estratégia (MINAYO, 2006). A organização do conteúdo em

${ }^{4}$ Os relatórios referentes aos Eventos (Ex. Ironman e WQS - divisão de acesso ao Circuito Mundial de Surf) não foram disponibilizados e para informações sobre os Projetos Sociais, obteve-se os contatos telefônicos dos responsáveis. 
categorias, em função do tema e da significação das informações, é apresentada de forma sintetizada conforme segue: orientações políticas: políticas genéricas e esporte de rendimento; atendimento generificado e naturalização.

\section{ORIENTAÇões POLítICAS: POLítICAS GENÉRICAS E ESPORTE DE RENDIMENTO}

Neste momento procuramos destacar e refletir sobre as perspectivas que orientam os sujeitos na sua prática profissional e que reflete a própria Fundação. Para tanto, cabe destacar que seis sujeitos são graduados ou pós-graduados na área de educação física, um deles possui ensino médio e um é graduado em história. Ao serem perguntados sobre como percebiam a organização/formulação e as ações políticas da FME no que se refere ao gênero, os sujeitos entrevistados expressaram o seguinte:

Em relação a homens e mulheres eu acho que não tem diferença nenhuma. É aberto o mesmo espaço, mesma atenção é dada, mesma necessidade existe, então, esporte para todos (Tiago) ${ }^{5}$.

[...] todo mundo é igual, todo mundo tem acesso livre (Lucas).

Eu não vejo a distinção de homens e mulheres, volto a configurar a importância tanto de homens e mulheres nas atividades esportivas. Em termos de rendimento são iguais, vão trazer as mesmas pontuações, então não tem como fazer a distinção [...] Então, numa competitividade, seja homem, seja mulher, vão ter a mesma importância para a delegação de Florianópolis (Davi).

Eu vejo de uma forma muito boa a participação de todos. Os resultados também são bons tanto no masculino como no feminino. $\mathrm{O}$ incentivo a equipes femininas e masculinas é igual, o que eu quero é que todos pratiquem (João).

${ }^{5}$ Utilizamos nomes fictícios para garantir o direito ao anonimato dos sujeitos.

Movimento, Porto Alegre, v. 19, n. 03, p. 57-78, jul/set de 2013. 
Inicialmente observa-se que os sujeitos acreditam que a FME tem promovido uma política esportiva igualitária em relação ao gênero, ao expressarem que há o "acesso livre", "o incentivo igual", e que a "mesma necessidade existe" para homens e mulheres. No entanto, tal discurso faz questionar se a orientação da FME não caminha mais no sentido da promoção de políticas genéricas, do que sensíveis ao gênero, para utilizar o termo sugerido por Stromquist (1996). Neste caso as políticas genéricas representariam políticas gerais e supostamente neutras que se estabelecem para a globalidade da população, sem considerar suas diversidades, já as políticas sensíveis ao gênero seriam aquelas que, neste caso, promoveriam iguais condições de acesso e permanência de ambos os sexos nas práticas de esporte e lazer reconhecendo e incluindo as diferenças. Farah (2003, p.1) esclarece a real dimensão desta diferença ao explicar que "Trata-se de reconhecer a diversidade e a diferença - entre homens e mulheres - mas atribuindo a ambos 'igual valor', reconhecendo, portanto, que suas necessidades 'específicas`e nem sempre 'iguais` devem ser igualmente contempladas pela sociedade e pelo Estado". Sendo assim podemos questionar se adotar a postura da "igualdade", tal como expressaram os sujeitos, é um direcionamento suficiente para garantir a igualdade entre os sexos nas políticas esportivas.

Outro aspecto que podemos observar é que para os sujeitos entrevistados a suposta igualdade nas políticas de esporte e lazer relaciona-se diretamente às competições nas quais a Fundação participa representando Florianópolis. Sobre isso, também é interessante a seguinte fala:

Então a participação delas também é boa aqui na Fundação. Na verdade é que tem mais provas que são masculinas, no caso do remo, do ciclismo né, o tiro. São três troféus que são só masculinos, que na verdade é livre mas participa só homem (Pedro). 
Assim como Pedro, a maioria dos sujeitos refere-se aos Jogos Abertos de Santa Catarina (JASC), principal competição da FESPORTE $^{6}$ para explicar que a promoção de esporte e lazer se dá igualmente para ambos os sexos. No entanto, os dados de campo permitiram evidenciar que o fato de haver equipes femininas e masculinas representando o município de Florianópolis em tais competições não é garantia de igualdade para ambos os sexos. Por exemplo, seria preciso considerar os motivos de haver menos equipes femininas de cada modalidade participando das etapas anteriores a etapa final das competições, o fato de não haver times femininos em algumas modalidades nas competições estaduais, o que justifica também a falta de desenvolvimento da modalidade em níveis de base (iniciação esportiva) ou como lazer e ainda que não há participação de equipes representativas da Fundação em modalidades que, apesar de serem oferecidas no JASC, não contam pontuação para a classificação geral da cidade, como é exemplo o futebol feminino.

O que se percebe a partir das falas é que a importância e o desenvolvimento dos esportes femininos e masculinos estão condicionados ao retorno que podem proporcionar, em pontuação e classificação da cidade, nas competições, e que, portanto, a igualdade mencionada pelos sujeitos é pautada numa política esportiva externa, qual seja, as competições estaduais e nacionais, especialmente ao JASC. Assim, o parâmetro para a igualdade proferida pelos sujeitos é, na maioria das vezes, a participação da FME em todas as modalidades (femininas e masculinas) previstas e com pontuação, naquela competição.

Não apenas nas falas, mas nas proporções dos investimentos financeiros, o esporte de rendimento tem sido uma orientação política marcante não só no desenvolvimento das políticas da FME como nas políticas esportivas brasileiras como um todo, tanto como instrumento de manutenção de uma ordem social e econômica como

\footnotetext{
${ }^{6} \mathrm{~A}$ FESPORTE organiza as principais competições esportivas das quais a FME participa tais como: Jogos Abertos de Santa Catarina (JASC), Jogos Abertos Paradesportivos de Santa Catarina (PARAJASC) e Olimpíada Estudantil Catarinense (OLESC).
} 
forma de legitimar o Estado (BRACHT, 2005). Este direcionamento dificulta, não apenas o desenvolvimento de modalidades esportivas femininas, como também daquelas práticas corporais que, independentemente de quem as pratica, ainda não passaram pelo processo de esportivização e que não deveriam "ficar subordinadas ao modelo de esporte e moldarem-se nele para receber atenção do poder público" (BRACHT, 2005, p. 88).

Assim, entendemos que as orientações da FME pautadas em políticas genéricas e a prioridade conferida ao esporte na sua dimensão de rendimento, analisadas pela perspectiva do gênero, podem refletir em desigualdades.

\section{ATENDIMENTO GENERIFICADO}

Após discutir algumas das orientações da política esportiva da FME, segue-se para uma reflexão que permeará ainda mais o plano da concretude, partindo tanto da perspectiva dos sujeitos como dos dados levantados por meio do estudo dos relatórios de atividades disponibilizados.

Apesar de defenderem que as políticas promovidas pela Fundação são igualitárias quanto ao sexo, os sujeitos também concordam que, de uma maneira geral, há mais homens participando das atividades como beneficiários. Esta constatação fica mais evidente quando se acrescenta as informações da Tabela 01, sobre o número de atendimentos de homens e mulheres em algumas ações da FME. 
Tabela 1 - Quantidade de atendimentos de homens

e mulheres pela FME em 2009.

\begin{tabular}{|c|c|c|}
\hline Atividades & Mulheres & Homens \\
\hline $\begin{array}{l}\text { Projeto Samba Fil ho da Lua } \\
\text { Modalidade: Futsal } \\
\text { Idade: } 7 \text { à } 17 \text { anos }\end{array}$ & 0 & 200 \\
\hline $\begin{array}{l}\text { Projeto Karatê Cidadania } \\
\text { Modalidade: Karatê } \\
\text { Idade:7 à } 17 \text { anos }\end{array}$ & 195 & 305 \\
\hline $\begin{array}{l}\text { Projeto de Integração pelo Esporte (PIPE) } \\
\text { Modalidade: vol eibol } \\
\text { Idade: } 10 \text { à } 16 \text { anos }\end{array}$ & 35 & 30 \\
\hline $\begin{array}{l}\text { Jogos Abertos de Santa Catarina (JASC) } \\
\text { Modalidade: várias } \\
\text { Idade: Livre }\end{array}$ & 80 & 191 \\
\hline $\begin{array}{l}\text { Joguinhos Abertos } \\
\text { Modalidade: várias } \\
\text { Idade: de } 15 \text { a } 19 \text { anos }\end{array}$ & 167 & 184 \\
\hline $\begin{array}{l}\text { Olimpíadas Estudantis de Sant a Catarina } \\
\text { (OLESC) } \\
\text { Modalidade: várias } \\
\text { Idade: de } 14 \text { a } 16 \text { anos } \\
\end{array}$ & 48 & 59 \\
\hline $\begin{array}{l}\text { Jogos Paradesportivos de Santa Catarina (PARA } \\
\text { JASC) } \\
\text { Modalidade: várias } \\
\text { Idade: Livre }\end{array}$ & 22 & 39 \\
\hline $\begin{array}{l}\text { Olimpíada Estudantil de Florianópolis (OLESF) } \\
\text { Modalidade: várias } \\
\text { Idade: } 11 \text { à } 16 \text { anos }\end{array}$ & 772 & 1003 \\
\hline $\begin{array}{l}\text { Moleque Bom de Bola } \\
\text { Modalidade: futebol de campo } \\
\text { Idade: } 11 \text { à } 14 \text { anos }\end{array}$ & 120 & 400 \\
\hline TOTAL & $1.439-37,4 \%$ & $2.411-62,6 \%$ \\
\hline
\end{tabular}

A respeito da Tabela apresentada é preciso ressaltar que ela expressa somente as informações as quais se teve acesso, mostrando as diferenças nas participações de homens e mulheres como beneficiários nos projetos sociais, nas competições estaduais e escolares. A Tabela fornece alguns indicativos importantes e concretos, como o desequilíbrio entre o atendimento ao público masculino $(62,6 \%)$ e ao feminino $(37,4 \%)$, tanto nas atividades direcionadas ao público infantil, como ao público juvenil e adulto. Esta diferença quantitativa também é observada em outros estudos que analisam as práticas esportivas e de lazer, tais como o de SallesCosta et al (2003) e Goellner et al (2009). 
Apesar desses estudos não tratarem especificamente de políticas públicas, contribuem ponderando sobre fatores que interferem para uma maior ou menor adesão de homens, mulheres, meninos e meninas nas práticas lúdicas e esportivas. Sob a perspectiva da divisão social do trabalho Salles-Costa et al (2003) e Goellner et al (2009) argumentam que o trabalho doméstico ainda é atribuído às mulheres e as meninas, de forma a multiplicar sua jornada de trabalho, tendo assim o tempo de lazer diminuído. Este aspecto é reforçado por uma pesquisa do Instituto de Pesquisa Econômica Aplicada (2010), que constatou que a entrada da mulher no mercado de trabalho não diminui o seu tempo dedicado às atividades domésticas ${ }^{7}$, e que, mesmo tendo mais tempo de escolaridade, o salário das mulheres trabalhadoras continua sendo inferior (IBGE, 2010) ${ }^{8}$. Assim, o aspecto econômico também aparece como um fator importante, pois a renda familiar per capita mais elevada aparece como um favorecedor das práticas corporais para ambos os sexos, mas particularmente entre as mulheres, já que possibilita que elas adquiram produtos e serviços que as liberem por mais tempo das atividades domésticas (SALLESCOSTA et al, 2003).

A reflexão sobre os fatores apresentados e a tomada de consciência sobre suas interferências no que diz respeito ao acesso e permanência de homens e mulheres nas práticas corporais podem ser indicativos que ajudam a entender e criar estratégias para a democratização das políticas pública do setor, já que "[...] a identificação concreta das formas como se manifestam as desigualdades de gênero permite identificar prioridades de ação" (FARAH, 2003 p. 3). Sendo assim, mais do que estabelecer políticas gerais, que supostamente favoreçam homens e mulheres igualmente, é necessário criar estratégias que atentem as suas diferentes necessidades. Neste sentido, poderia se pensar em ações de incentivo,

\footnotetext{
${ }^{7} \mathrm{O}$ comunicado do Instituto de Pesquisa Econômica Aplicada (IPEA) tem como base dados do Instituto Brasileiro de Geografia e Estatística (IBGE) que mostram que as mulheres trabalham 23,9 horas semanais em atividades domésticas, contra 9,7 horas para os homens.

${ }^{8}$ As mulheres trabalhadoras com ensino médio são $61,2 \%$, para $53,2 \%$ dos homens. Com nível superior são $19,6 \%$ de mulheres e $14,2 \%$ dos homens. Apesar de mais tempo de estudos, as mulheres recebem remuneração equivalente a $72,3 \%$ do que recebem os homens.
} 
como disponibilizar e buscar preencher a mesma quantidade de vagas para ambos os sexos, seja em projetos de iniciação esportiva, competições ou de lazer, bem como diversificar horários e locais de atividades, ou pensar em ações que integrem toda família e atendam ao mesmo tempo mães, pais e filhos, flexibilizando a participação de homens e mulheres na atividade em relação às suas jornadas de trabalho.

Entendemos que problematizar a igualdade de gênero no campo esportivo e de lazer não se resume a questionar a quantidade de participações dos sexos, o que visivelmente vem se equiparando, mas também a qualificação das participações. Além do reconhecimento de maior atendimento masculino nas atividades, de um modo geral, os sujeitos observam diferenças nas preferências de homens e mulheres, tal como explicam:

Então a mulher ela participa levando os filhos. Aí se fizer atividades de desfile, de produtos recicláveis, aí a mulher é mais efetiva. Já em termos de corrida a participação da mulher já é menor (Pedro).

As mulheres são muito mais abertas para esta questão de participar, e tem também aquela coisa de gostar de fazer ginástica, de caminhar. [...] elas são muito mais participativas nestes eventos de lazer do que de competição, porque eu vejo na competição esta questão mais do conflito, do confronto, nesse grupo...(Lucas).

Mesmo destacando a presença e o gradativo aumento do número de mulheres nas competições e em modalidades tidas como masculinas, os sujeitos destacam a maior participação feminina em atividades de cunho mais cooperativo, como as ginásticas recreativas, as atividades para terceira idade e de lazer, enquanto que a maior participação masculina se dá em eventos esportivos competitivos e em modalidades como remo, futebol, ciclismo, corridas e lutas, preferências que também se alinham aos dados de estudos já citados (SALLES-COSTA et al., 2003; GOELLNER et al., 2009). 
Como visto, a prioridade da FME são as competições esportivas de rendimento, as quais contemplam em maior medida as atividades que os próprios sujeitos relacionam a maior participação masculina. No caso das atividades citadas como de maior público feminino, identificamos apenas três: um projeto itinerante de equipamentos e brinquedos infláveis - única atividade de lazer desenvolvida continuamente pela FME-, os Jogos Abertos da Terceira Idade (JASTI) - evento promovido pela FESPORTE, e as Academias da saúde - equipamentos para exercício físico instalado ao ar livre. Quanto às ginásticas recreativas e danças, atividade citada como de preferência feminina, não foram encontradas ações promovidas pela Fundação. Parte desta evidência deve-se, como já foi discutido, ao fato destas práticas normalmente não se moldarem aos tradicionais conceitos de esporte e, portanto não proporcionarem os mesmos retornos.

Ao falar-se de preferências masculinas e femininas quanto às práticas corporais, não se está fazendo generalizações, pois também há mulheres que apreciam atividades competitivas e modalidades como lutas e futebol, como também há homens que apreciam as atividades corporais de cunho mais cooperativo ou expressivo, mesmo que estas não sejam as configurações predominantemente disseminadas e aceitas socialmente. A ideia de que homens e mulheres podem ter interesses diversos, não necessariamente diferentes, precisa ser levado em consideração pelas políticas estatais para que ambos tenham iguais condições de acesso, não apenas àquilo que se tem como interesses de cada grupo, mas àquilo que se tem como interesses humanos sobre os conteúdos da cultura corporal.

Tanto as considerações sobre "preferências" de ambos os sexos em relação às práticas corporais, como os aspectos econômicos e da divisão social do trabalho, poderiam ser melhor esclarecidas e talvez minimizadas se as relações entre Estado e sociedade civil fossem estreitadas por meio da participação popular.

A oportunidade de participação nos processos de tomada de decisão tem sido vista como essencial para a inclusão de interesses de grupos diversos como o de mulheres e de negros nas agendas 
governamentais, acarretando numa melhor adequação das políticas às necessidades e direitos destes grupos (ABRAMO, 2004). Esta adequação estabelece-se pelo maior contato dos gestores com a realidade, pelo conhecimento dos interesses e aspirações da sociedade e atendimento as suas reivindicações, diminuindo as tendências de valorizar preferências pessoais e políticas (MARCELLINO, 1996). A Fundação Municipal de Florianópolis ainda não apresenta na prática a abertura destes canais de comunicação, apesar de a constituição do Conselho Municipal de Esporte já estar aprovada legalmente desde 2009, mas sem funcionamento até o momento.

\section{Naturalização}

Além de relatarem sobre as perspectivas da Fundação, as preferências e disparidades numéricas em relação à participação de homens e mulheres nas ações promovidas pela Fundação, os sujeitos trazem falas que podem ser analisadas como justificativas para o que observamos até então:

Mas é natural que tenham mais homens, até porque tem mais modalidades masculinas [...] Acho que homens têm mais disposição. Ele tem mais energia, eu acho. [...] não é nada de machismo, mas tem esse lado aí, uma predisposição para determinadas situações (Matias).

A participação dela vem crescendo, mas sempre tem mais homens. Tem evento que ela tem mais identificação, no vôlei elas vão para ver os jogadores bonitões, famosos (Caio).

Existe um pouco sim, mas talvez exista, acredito eu, pela própria cultura da mulher, de ela participar menos, de procurar menos, mas não por problemas nossos, nem do educador, nem da FME (Raul).

Pelo uso de termos como "predisposição" e "identificação", pela forma como foram indicados comportamentos de cada sexo e, também, pela menção à "cultura da mulher", as falas dos 
entrevistados sugerem a defesa de certa "naturalização" das práticas e das formas de ser homem e ser mulher, evidenciando possíveis concepções aprendidas e interiorizadas por meio de processos sociais e institucionais. São concepções que se tornam, paulatinamente, "naturais", como se o sexo determinasse os comportamentos e as preferências humanas. A justificativa pautada na "natureza" colada às identidades de gênero é fruto do pensamento dicotômico binário (BOURDIEU, 1999), no qual masculino e feminino são pensados como conceitos opostos, fixos e hierarquizados, pensamento que também perpassa os modos de vivenciar as práticas corporais. Estas "divisões arbitrárias", que acabam adquirindo reconhecimento, "perdem força e legitimidade diante da percepção de que se traduzem em construções discursivas atreladas a redes de significação e de poder" (GOELLNER, 2007, p.188).

As falas dos sujeitos reafirmam a necessidade de desnaturalizar estas construções usadas como justificativas para as desigualdades de gênero no esporte e no lazer. O desafio é reconhecer que o futebol, por exemplo, mesmo sendo uma preferência masculina, também figura entre as preferências de muitas mulheres, o mesmo podemos dizer das modalidades e atividades tidas como femininas, por exemplo, a ginástica. A lógica da naturalização dos aspectos culturais, presente na fala dos sujeitos, encobre as desigualdades construídas historicamente, acabando por, mesmo que de forma velada, culpabilizando as mulheres por participarem menos das práticas esportivas e desresponsabilizando as instituições que assumem uma posição supostamente neutra.

Ao conjeturar que não há uma determinação natural dos comportamentos de homens e mulheres, o uso do conceito de gênero permite que as desigualdades sejam reduzidas em diversos espaços (FARAH, 2003), inclusive nas políticas públicas de esporte e do lazer, desde que este entendimento seja levado em conta no momento da elaboração e implementação das políticas. 


\section{CoNSIDERAÇõES FINAIS}

Ao longo desta pesquisa procuramos entender como o Estado, especificamente a FME, têm incorporado as questões de gênero na sua política de esporte e lazer. De um modo geral, as evidências permitem compreender que a FME têm desenvolvido suas políticas de forma genérica, ou seja, está estabelecido o discurso e a prática da igualdade que não reconhece as diferenças e as diversidades. Também ficou evidente que prevalece a perspectiva da naturalização dos aspectos culturais, baseada num determinismo biológico que justifica as diferenças na quantidade e nas preferências de homens e mulheres como beneficiários das políticas da Fundação.

Podemos dizer que há uma reduzida e frágil incorporação da perspectiva de gênero nas políticas públicas da FME, o que encaminha para um atendimento generificado, não apenas pelo número diferenciado de atendimentos de cada sexo, mas também: pela valorização diferenciada às dimensões esportivas e atividades de lazer, já que as atividades identificadas como de maior participação feminina carecem de iniciativas, seja em relação à ampliação dos serviços, seja na diversificação destes; pela desconsideração das diferenças de gênero que se referem à divisão social do trabalho e suas implicações no acesso e permanência de homens e mulheres nas atividades da Fundação.

Acreditamos que um olhar atento e treinado para perceber novas dimensões das desigualdades de gênero nas práticas coporais e que concretizem políticas sensiveis ao gênero são possíveis, e como desafios desta tarefa estão a descentralização do poder decisório com abertura de canais que permitam a participação dos diversos segmentos sociais no desenvolvimento das ações públicas e o acesso de mulheres aos altos cargos de comandos e eletivos, além de, principalmente, a conscientização e capacitação dos atores políticos e sociais para a inclusão da temática de gênero nas políticas públicas. 
Gender relationship in Fundação Municipal de Esportes de Florianópolis: generic policies, gender tretment.

Abstract:This research was developed in Fundação Municipal de Esportes de Florianópolis, Santa Catarina (Brazil) in order to understand how gender issues are incorporated (or not) in public policies for sport and leisure in that institution. Interviews with managers and technicians of the Fundação and analyzes of activity reports has pointed that there is more concern to men than women, which is attribut to the differentiated valuation of modalities and dimensions of sports; for interviewed the policies are equal between men and women, and the higher male participation is attributed to cultural aspects, which are naturalized by them.

Keywords: Gender. Public policy. Sports. Leisure.

Las relaciones de gênero en la Fundação Municipal de Esportes de Florianópolis: políticas genéricas, tratamiento generificado.

Resumen: Esta investigación se llevó a cabo en lá Fundação Municipal de Esportes de Florianópolis, Santa Catarina (Brasil) con el fin de comprender cómo las cuestiones de género se incorporan (o no) en las políticas públicas para el deporte y el ocio de la institución. Las entrevistas con líderes y técnicos de la Fundação y las análisis del informe de actividades ha señalado que existe una mayor atención a los hombres que las mujeres, que viene dada por la valoración diferente de las dimensiones de deportes; para los entrevistados hay igualdad en las políticas, y la mayor participación masculina se atribuye a los aspectos culturales, que son naturalizados por ellos. Palabras clave: Género. Políticas públicas. Deportes. Ocio. 


\section{REFERÊNCIAS:}

ABRAMO, Laís. Perspectiva de gênero e raça nas políticas públicas. Mercado de trabalho, Distrito Federal, n. 24, p. 17-21, nov. 2004. Disponível em: <http:// www.ipea.gov.br/pub/bcmt/mt_25e.pdf> Acesso em: 10 jul. 2010.

BOGDAN, Robert; BIKLEN, Savi. Investigação qualitativa em educação: uma introdução à teoria e aos métodos. Porto: Porto, 2003.

BOURDIEU, Pierre. A Dominação Masculina. Tradução Maria Helena Khuner. Rio de Janeiro: Bertrand Brasil, 1999.

BRACHT, Valter. Sociologia crítica do esporte: uma introdução. 3. ed. Ijuí: Unijuí, 2005.

BRASIL. Decreto- Lei n. 3.199 de 14 de Abril de 1941. Estabelece as bases de organização dos desportos em todo o país., 1941. Diário Oficial da União, Rio de Janeiro, 1941. Disponível em:< http://www6.senado.gov.br/sicon/\#> Acesso em 5 mar. 2009.

BUTLER, Judith. Problemas de gênero. Rio de Janeiro: Civilização Brasileira, 2003.

FARAH, Marta. F. Santos. Gênero e políticas públicas. In: SEMINÁRIO NACIONAL DE COORDENADORIAS DAMULHER NO NÍVEL MUNICIPAL: o Governo da Cidade do ponto de vista das Mulheres. 2003, São Paulo. Anais Seminário Nacional de Coordenadorias da Mulher no Nível Municipal. São Paulo: PMSP, 2003. v. 1, p. 1-17.

FARAH, Marta. F. Santos. Gênero e políticas públicas. Estudos Feministas, Florianópolis, v. 12, n. 1, p. 47-71, jan./abr.2004.

GOELLNER, Silvana V. Feminismos, mulheres e esportes: questões epistemológicas sobre o fazer historiográfico. Movimento, Porto Alegre, v.13, n. 02, p.171-196, mai./ago. 2007.

GOELLNER, Silvana V.. Mulheres e futebol no Brasil: entre sombras e visibilidades. Revista Brasileira de Educação Física e Esporte, São Paulo, v. 19, n. 2, p. 143151, abr./jun. 2005.

GOELLNER, Silvana V.. Mulher e esporte no Brasil: entre incentivos e interdições elas fazem história. Pensar a prática, Goiânia, v. 8, n 1, p. 85 - 100, jan./jun. 2005b. 
GOELLNER, Silvana V. et al.. Lazer e gênero: considerações iniciais a partir da experiência do Programa Esporte e Lazer da Cidade. In: FRAGA Alex B. et al. Políticas de lazer e saúde em espaços urbanos. Porto Alegre, Gênese, 2009. p.53 - 61.

IBGE. Instituto Brasileiro de Geografía e Estatística. Pesquisa Mensal de EmpregoPME. Mulher no mercado de trabalho: perguntas e respostas, 2010. Disponível em: <http://www.ibge.gov.br/home/estatistica/indicadores/trabalhoerendimento/ pme_nova/Mulher_Mercado_Trabalho_Perg_Resp.pdf>. Acesso em: 8 mar. 2010.

IPEA. Instituto de Pesquisa Econômica e Aplicada. Comunicado do Ipea no 40 . Mulher e Trabalho: avanços e continuidades, 2010. Disponível em: <http:// agencia.ipea.gov.br/images/stories/PDFs/100308_comu40mulheres.pdf>. Acesso em 8 mar. 2010.

LINHALES, Meily Assbú. A trajetória política do esporte no Brasil: interesses envolvidos, setores excluídos.1996. 242 f. Dissertação (Mestrado em Ciência Política) - Faculdade de Filosofia e Ciências Humanas, Universidade Federal de Minas Gerais, Belo Horizonte, 1996.

LOURO, Guacira L. Gênero, sexualidade e educação: uma perspectiva pós estruturalista. 5. ed. Petrópolis: Vozes, 1997.

LYRA-DA-FONSECA, Jorge Luiz C. Homens, feminismo e direitos reprodutivos no Brasil: uma análise de gênero no campo das políticas públicas (2003-2006). 2008. 231f. Tese (Doutorado em Saúde Pública) - Centro de Pesquisas Aggeu Magalhães, Fundação Oswaldo Cruz, Recife, 2008.

MARCELLINO, Nelson C. Políticas públicas setoriais de lazer: o papel das prefeituras. Campinas: Autores Associados, 1996.

MENICUCCI, Telma. Políticas públicas de lazer: questões analíticas e desafios políticos. In: ISAYAMA, Helder; LINHALES, Meily. (org). Sobre lazer e política: maneiras de ver, maneiras de saber. Belo Horizonte: Ed UFMG, 2006. p. 136-164.

MINAYO, Maria Cecilia de Souza . O desafio do conhecimento: pesquisa qualitativa em saúde. 9. ed. São Paulo:Hucitec-Abrasco, 2006.

SALLES-COSTA, Rosana et al. Gênero e prática de atividade física de lazer. Cad. Saúde Pública, Rio de Janeiro, v. 19, supl. 2, s325 - s333, 2003.

SCOTT, Joan. Gênero: uma categoria útil de análise histórica. Educação e Realidade, Porto Alegre, v. 15, n. 2, p. 5-22, jul./dez., 1990.

STROMQUIST, Nelly P. Políticas públicas de Estado e eqüidade de gênero: perspectivas comparativas. Tradução de Vera M.D. Renoldi. Revista Brasileira de Educação. São Paulo, n. 1, p. 27-49, jan./abr. 1996. 
VIANNA, Cláudia. P.; UNBEHAUM Sandra. O gênero nas políticas públicas de educação no Brasil: 1988-2002. Cadernos de Pesquisa, Rio de Janeiro, v. 34, n. 121, p. 77-104, jan./abr. 2004. Disponível em: <http://www.scielo.br/pdf/cp/v34n121/ a05n121.pdf> Acesso em 20 ago. de 2010.

Apoio: Pesquisa financiada pelo Conselho Nacional de Desenvolvimento Científico e Tecnológico (CNPq)

Endereço para correspondência:

Verônica Werle

Rua Almirante Alvim, 452. Apto 601-A

Florianópolis - SC

CEP 88015380

Recebido em: 22.08.2012

Aprovado em: 19.01.2013 